\title{
Effect of Self-Medication with Antimalarial Drugs on Malaria Infection in Pregnant Women in South-Western Nigeria
}

\author{
O.M. Akanbi a,b A.B. Odaibo ${ }^{\text {b }}$ K.A. Afolabi ${ }^{d}$ O.G. Ademowo ${ }^{c}$ \\ aDepartment of Environmental Biology and Fisheries, Faculty of Science, Adekunle Ajasin University, \\ Akungba-Akoko, Ondo State, 'b Department of Zoology, Parasitology Unit, Faculty of Science, University of Ibadan, \\ and 'Institute of Advanced Medical Research and Training, College of Medicine, University of Ibadan, \\ Ibadan, Nigeria; ${ }^{\mathrm{d} A d e-O y o ~ M a t e r n i t y ~ S t a t e ~ H o s p i t a l, ~ Y e m e t u, ~ I b a d a n, ~ N i g e r i a ~}$
}

\section{Key Words}

Pregnancy - Chloroquine - Pyrimethamine •

Primigravidae $\cdot$ Multigravidae $\cdot$ Packed cell volume .

Self-medication

\begin{abstract}
Objective: To determine the effect of self-medication with chloroquine and pyrimethamine on malaria infection and anaemia during pregnancy. Subjects and Methods: The study involved 210 women who attended Ade Oyo Maternity State Hospital, Ibadan, Nigeria. Of these, 156 were pregnant women while 54 were not pregnant (controls). Of the pregnant women, 66 were primigravidae, while 90 were multigravidae. History of treatment of malaria with antimalarial drugs was obtained from the subjects. Gravidity and gestation period were also documented. Two millilitres of blood was withdrawn from each subject, for haematological parameters. Thin and thick films were prepared for malaria parasite identification and quantification. Results: Of the primigravidae and multigravidae 68 and $16.4 \%$, respectively, had taken antimalarial drugs prior to booking. Among primigravidae, only $18 \%$ of those with drugs compared with $32 \%$ without drugs were malaria-positive. The parasite density was significantly lower among those who took anti-
\end{abstract}

\section{KARGER}

Fax +41613061234

E-Mail karger@karger.ch

www. karger.com

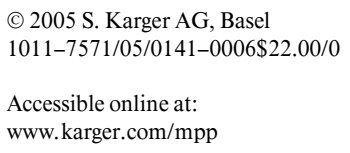

malarial drugs than among those who did not $(976 \pm 60$ versus $2,421 \pm 78, p<0.05)$. Similarly, among multigravidae, only $16.4 \%$ of those who took antimalarial drugs compared with $34 \%$ of those who were not malaria-positive. The parasite density was also significantly lower in multigravidae with drugs than among those without drugs ( $350 \pm 45$ versus $1,000 \pm 65, p<0.05)$. The prevalence of anaemia (packed cell volume, PCV $<33$ ) was high, $89 \%$ in primigravidae and $70 \%$ in multigravidae. Severe anaemia (PCV <21) was more common in malaria-positive primigravidae and multigravidae than in malaria-negative women. Conclusion: The findings indicate that self-medication with chloroquine and pyrimethamine at booking was able to reduce the prevalence of malaria and anaemia in pregnancy.

Copyright $@ 2005$ S. Karger AG, Basel

\section{Introduction}

Despite continued efforts to control malaria, it remains a major health problem in many regions of the world, especially sub-Saharan Africa, causing severe disease mainly in children and pregnant women [1]. Pregnant women constitute an important high risk group for malaria infection [2], as malaria parasites increase risk of 
maternal anaemia, abortion, still-birth, prematurity, intra-uterine growth retardation and low birth weight [3]. Incidence of malaria infection in pregnancy is known to be higher in primigravidae than in multigravidae [2]. Malaria during the first pregnancy causes a high rate of fetal and neonatal death. The decreasing susceptibility during subsequent pregnancies correlates with acquisition of antibodies that block binding of infected red cells to chondroitin sulphate-A [4].

Severe anaemia in pregnancy is an important contributor to maternal and perinatal morbidity and mortality [1]. Malaria-related deaths in primigravidae are associated with severe anaemia [5]. Though the causes of anaemia in pregnancy are preventable, the overall prevalence of anaemia has not changed for many years. This may be due to operational problems and inadequate interventions [6]. Control interventions thus need to be targeted at pregnant women in malaria-endemic areas [7]. As pregnancy is associated with increased incidence and adverse outcome of Plasmodium falciparum malaria infection, chemoprophylaxis should be made an integral part of antenatal care along with antimalarial therapy to reduce the risk of serious maternal and fetal complications [8]. Some studies have shown that the majority of pregnant women in malaria endemic areas who took antimalarial drugs on self-medication prior to booking at an antenatal clinic have a lower parasite density than those who did not [9]. The intermittent treatment with the antimalarial sulphadoxine-pyrimethamine, given a couple of times during pregnancy, has been found to reduce severe anaemia in primigravidae by $39 \%$ in Kenya [7]. Therefore, this study was carried out to investigate the effect of self-medication with the antimalarial drugs chloroquine and pyrimethamine prior to booking at an antenatal clinic on malaria infection and anaemia in pregnancy.

\section{Subjects and Methods}

\section{Study Group}

Two hundred and ten women who gave informed consent were recruited for this study. One hundred and fifty-six were pregnant women who came to the antenatal clinic and 54 were non-pregnant women (controls) who came for normal routine medical check at Ade-Oyo, State Maternity Hospital, Ibadan, Nigeria. Both groups were of similar socio-economic groups and age. Of the pregnant women, 66 were primigravidae while 90 were multigravidae. History of treatment of malaria during the preceding week with any form of antimalarial chemotherapy and chemoprophylactic agent were obtained from the subjects. Other pertinent data obtained from the patients included: age, parity, number of still-births, and last menstrual period. Gestational age was obtained from the last menstrual
Table 1. Mean parasite density among pregnant and non-pregnant women in south-western Nigeria

\begin{tabular}{lccc}
\hline & Women & Infected & Parasite density \\
\hline Primigravidae & $66(31)$ & $15(22.7)$ & $3,134 \pm 107$ \\
Multigravidae & $90(43)$ & $21(23.3)$ & $1,014 \pm 158$ \\
Non-pregnant & $54(26)$ & $5(9.3)$ & $308 \pm 70$ \\
\hline Total & $210(100)$ & $41(19.5)$ &
\end{tabular}

Note that parasite density is significantly higher in primigravidae than in multigravidae, and it is also significantly higher in primigravidae and multigravidae than in the controls, $\mathrm{p}<0.05$. Figures in parentheses are percentages.

period. Those who were transfused 2 months before the period of collection of samples were excluded, and those who were malariapositive were treated according to the WHO regulation. The study was done during the dry season.

\section{Blood Collection}

Two millilitres of blood was drawn by venipuncture into ethylenediaminetetraacetic acid anticoagulant bottles. The blood was used to estimate the packed cell volume (PCV).

Thick and thin films were made for each patient. The thin film was fixed with methanol and the slide then flooded with Giemsa stain diluted 1 in 10 with buffer $\mathrm{pH} 7.2$ for $20 \mathrm{~min}$. Malaria parasites were identified and counted using a light microscope. A slide was considered negative only when no parasite was seen after screening at least 200 fields. For the positive slides, the number of parasites counted per 200 white blood cells was recorded and used to calculate parasite density on the basis of 8,000 leucocytes/ $\mu 1$ of blood [10].

Severe anaemia and moderate anaemia were defined as PCV values of $<21$ and $21-32.9 \%$, respectively, while PCV of $33 \%$ or more was considered normal [11]. Data were presented as percentages, means and standard deviations. Means were compared by using Student's $t$ test. Calculated $\mathrm{p}$ value $\leq 0.05$ was considered significant.

\section{Results}

The mean parasite density in both pregnant and nonpregnant women is given in table 1 . Fifteen $(22.7 \%)$ of the primigravidae, $21(23.3 \%)$ of the multigravidae and 5 $(9.3 \%)$ of non-pregnant women were malaria-positive. The mean parasite density was significantly higher in primigravidae than in multigravidae $(3,134 \pm 107$ versus $1,014 \pm 158 ; \mathrm{p}<0.05)$. The mean parasite densities were also significantly higher in both primigravidae and multigravidae than in non-pregnant controls, respectively $(3,134 \pm 107$ and $1,014 \pm 158$ versus $308 \pm 70 ; p<0.05)$ as shown in table 1. 
Table 2. Self-medication with chemoprophylaxis and parasite density in pregnancy in south-western Nigeria

\begin{tabular}{|c|c|c|c|c|c|c|}
\hline & \multicolumn{3}{|c|}{$\begin{array}{l}\text { Women with chemoprophylaxis } \\
\text { before antenatal clinic }\end{array}$} & \multicolumn{3}{|c|}{$\begin{array}{l}\text { Women without chemoprophylaxis } \\
\text { before antenatal clinic }\end{array}$} \\
\hline & $\mathrm{n}$ & $\begin{array}{l}\text { malaria- } \\
\text { positive }\end{array}$ & $\begin{array}{l}\text { parasite } \\
\text { density }\end{array}$ & $\mathrm{n}$ & $\begin{array}{l}\text { malaria- } \\
\text { positive }\end{array}$ & $\begin{array}{l}\text { parasite } \\
\text { density }\end{array}$ \\
\hline Primigravidae & $45(68)$ & $8(18)$ & $976 \pm 60$ & $21(32)$ & $7(33.3)$ & $2,421 \pm 78$ \\
\hline Multigravidae & $55(61)$ & $9(16.4)$ & $350 \pm 45$ & $35(39)$ & $12(34)$ & $1,000 \pm 65$ \\
\hline Non-pregnant & $5(27)$ & $1(7)$ & $210 \pm 20$ & $39(63)$ & $4(10.26)$ & $350 \pm 40$ \\
\hline Total & 105 & $18(17)$ & & 85 & $23(27)$ & \\
\hline
\end{tabular}

Figures in parentheses are percentages.
Table 3. PCV in relation to parasitaemia

\begin{tabular}{llllll}
\hline PCV & \multicolumn{2}{l}{ Primigravidae } & & \multicolumn{2}{l}{ Multigravidae } \\
\cline { 2 - 3 } \cline { 5 - 6 } & $\begin{array}{l}\text { malaria- } \\
\text { positive }\end{array}$ & $\begin{array}{l}\text { malaria- } \\
\text { negative }\end{array}$ & & $\begin{array}{l}\text { malaria- } \\
\text { positive }\end{array}$ & $\begin{array}{l}\text { malaria- } \\
\text { negative }\end{array}$ \\
\hline$<21$ & $7(47)$ & $10(20)$ & & $6(29)$ & $5(7)$ \\
$21-32$ & $8(53)$ & $32(62)$ & & $12(57)$ & $40(58)$ \\
$\geq 32$ & - & $9(18)$ & & $3(14)$ & $24(35)$ \\
\hline Total & $15(22.7)$ & $51(77.3)$ & & $21(23.3)$ & $69(76.7)$ \\
\hline
\end{tabular}

Figures in parentheses are percentages.

Table 2 summarizes the effect of self-medication with antimalarial drugs (chloroquine or pyrimethamine) and other drugs such as folic acid, B complex, multivitamin. Only 8 of 45 (18\%) primigravidae who took antimalarial drugs prior to booking at the antenatal clinic were malaria-positive compared to 21 (33.3\%) who did not take antimalarial drugs. The mean parasite density was significantly lower in primigravidae who took chloroquine or pyrimethamine than in primigravidae who did not $(976 \pm 60$ versus $2,421 \pm 78 ; p<0.05$ ) but the PCV was not significantly different $(\mathrm{p}>0.05)$. Among multigravidae, only 9 of $55(16.4 \%)$ who took antimalarial drug were malariapositive compared to 12 of $35(34 \%)$ who did not. The mean parasite density was also significantly lower in those who took than those who did not take antimalarial drugs prior to booking at the antenatal clinic $(350 \pm 45$ versus $1,000 \pm 65 ; \mathrm{p}<0.05)$.

The parasite density was significantly higher in nonpregnant controls who did not take antimalarial drugs than those who did $(350 \pm 40$ versus $210 \pm 20)$.
The prevalence of anaemia ( $\mathrm{PCV}<33)$ was 89 and $70 \%$ in primigravidae and multigravidae, respectively $(\mathrm{p}<0.05)$. The prevalence of severe anaemia $(\mathrm{PCV}<21)$ was significantly higher in malaria-positive primigravidae than in malaria-positive multigravidae (47 versus $29 \%$; $\mathrm{p}<0.05$ ) as shown in table 3 .

\section{Discussion}

Prevalence of malaria infection is known to be usually significantly higher in pregnant than in the non-pregnant women living in the same endemic conditions $[9,12]$. The prevalence of malaria infection in pregnant women in this study was $23 \%$, compared to only $9 \%$ in non-pregnant women. Even though the prevalence was relatively low, this study has further established the fact that pregnant women are more susceptible to malaria infection than non-pregnant women. The reason for the low prevalence of malaria infection in this study could be due to the fact that the samples were collected in the dry season, which has been marked as a period of low malaria parasite transmission [13]. The results from this study show that parasite density was significantly higher in primigravidae than in multigravidae. This agrees with previous findings that gravidity influences the parasite densities [9, 14].

Self-medication is a practice that is very common among people living in malaria endemic areas. This study shows that the number of pregnant women who had taken antimalarial drugs before coming to the antenatal clinic was considerably higher than the number of those without drugs. This could be a result of awareness created through education on home management and control of malaria among the pregnant women, especially the primigravidae [7]. The parasite rate and parasite density in those without antimalarial drugs was significantly higher than in those 
with antimalarial drugs in both primigravidae and multigravidae, most probably because the antimalarial drugs were effective in killing the malaria parasite. This agrees with some previous findings that antimalarial drugs are associated with fewer malaria parasite infections [9]. The parasite density in this study was significantly higher in primigravidae with and without drugs than multigravidae with and without drugs. This is consistent with the finding of a higher susceptibility of primigravidae to malaria infection relative to multigravidae.

The harmful effect of malaria in pregnancy was evident in the higher incidence of anaemia among pregnant women than in controls. A recent study showed that most malaria-related deaths among primigravidae were associated with severe anaemia $[15,16]$. The majority of pregnant women in this study were anaemic. Severe anaemia was found among both malaria-positive primigravidae and multigravidae, but primigravidae were more severely anaemic than multigravidae. This is in accordance with other reports $[1,17]$. Malaria is, however, an underrecognized cause of anaemia in endemic areas as it is sometimes asymptomatic and may not be associated with peripheral parasitaemia [11].

\section{Conclusion}

The findings show that chemoprophylaxis is necessary in pregnancy especially among primigravidae, as they have been found to be more susceptible to malaria infection than the multigravidae, and that there is a need to intensify the home management awareness in the control of malaria infection in endemic areas particularly during pregnancy.

\section{References}

1 Brabin B: Malaria in pregnancy: Current issues. Afr Health 1997;19:19-20.

2 Graves P, Gelband H: Vaccine for preventing malaria. Cochrane Database Syst Rev 2000; CD000129.

-3 Kochar DK, Thanvi I, Joshi A, Subhakaran, Agarwal N, Jain N: Mortality trends in falciparum malaria: Effect of gender difference and pregnancy. J Assoc Physicians India 1999;47: 774-778.

$\checkmark 4$ Pouvelle B, Oishi S, Fujii N, Fusai T, Parzy D, Miller LH, Gysin J, Scherf A: Plasmodium falciparum domain mediating adhesion to chondroitin sulfate A: A receptor for human placental infection. Proc Natl Acad Sci USA 1999;96: 12743-12748.

$\checkmark 5$ Brabin BJ: An analysis of malaria in pregnancy in Africa. Bull WHO 1983;61:1005-1061.

6 Flemin AR, Ghatoura GBS: The prevention of anaemia in pregnancy in primigravidae in Guinea savanna of Nigeria. Ann Trop Med Parasitol 1986;80:211-233.

7 Shulman CE: Malaria in pregnancy: Its relevance to safe motherhood programmes. Ann Trop Med Parasitol 1999;93(suppl 1):S59_ S66.
8 Phillips-Howard PA: Epidemiological and control issues related to malaria in pregnancy. Ann Trop Med Parasitol 1999;93(suppl 1):S11S17.

9 Mockenhaupt FP, Rong B, Eggelte TA, Beck S, Gyasi-Sarpong C, Till H, William NT, Bienzle $\mathrm{U}$ : Submicroscopic Plasmodium falciparum infections in pregnancy in Ghana. Trop Med Int Health 2000;5:167-173.

10 Molineaux L: The epidemiology of human malaria as an explanation of its distribution, including some implications for its control; in Wernsdorfer YM, McGregor 1 (eds): Malaria: Principles and Practice of Malariology. Edinburgh, Churchill-Livingstone, 1988, pp 913998.

11 Arnorlu RI, Odum CU, Essien EE: Asymptomatic malaria parasitaemia in pregnant women at booking in a primary health care facility in a periurban community in Lagos, Nigeria. Afr J Med Sci 2001;30(suppl):39-41.
12 Ricke CH, Staalsoe T, Koram K, Akanmori BD, Riley EM, Theauder TG, Hviid L: Plasma antibodies from malaria-exposed pregnant women recognize variant surface antigens on Plasmodium falciparum-infected erythrocytes in a parity-dependent manner and block parasite adhesion to chondroitin sulfate A. J Immunol 2000;165:3309-3316.

13 Ukoli FMA (ed): Introduction to Parasitology in Tropical Africa. Chichester, Wiley \& Sons, 1990, pp 399-429.

14 Singh N, Shukla MM, Sharma VP: Epidemiology of malaria in pregnancy in central India. Bull WHO 1999;77:567-572.

15 Nosten F, Terkuile F, Maelankiri L, Decludt B, White NJ: Malaria during pregnancy in an area of unstable endemicity. Trans R Soc Trop Med Hyg 1991;85:424-429.

16 Granja AC, Machung F, Gomes A, Bergstrom $\mathrm{S}$, Brabin B: Malaria related maternal mortality in urban Mozambique. Ann Trop Med Parasitol 1998;92:257-263.

17 Bottius E, Guanzirolli A, Trape JF, Rogier C, Konate L, Druille P: Malaria: Even more chronic in nature than previously thought; evidence for subpatent parasitaemia detectable by polymerase chain reaction. Trans R Soc Trop Med Hyg 1996;90:15-19. 